\title{
MWCNT/Ti-doped ZnO nanocomposite as electrochemical sensor for detecting glutamate and ascorbic acid
}

\section{Siraprapa Pitiphattharabun}

Kasetsart University - Bangkhen Campus: Kasetsart University

Kornkamon Meesombad

National Science and Technology Development Agency

\section{Gasidit Panomsuwan}

Kasetsart University - Bangkhen Campus: Kasetsart University

Oratai Jongprateep ( $\nabla$ fengotj@ku.ac.th )

Kasetsart University - Bangkhen Campus: Kasetsart University

\section{Research Article}

Keywords: solution combustion synthesis, Ti-doped ZnO, electrochemical sensor, glutamate, ascorbic acid

Posted Date: May 4th, 2021

DOI: https://doi.org/10.21203/rs.3.rs-479428/v1

License: (c) (i) This work is licensed under a Creative Commons Attribution 4.0 International License. Read Full License

Version of Record: A version of this preprint was published at International Journal of Applied Ceramic Technology on September 13th, 2021. See the published version at https://doi.org/10.1111/ijac.13879. 


\section{Abstract}

Attributed to high stability and reproducibility, non-enzymatic electrochemical sensors have been extensively utilized in detection of various chemical substances. In this study, multi-walled carbon nanotube (MWCNT)/Ti-doped ZnO composite was prepared for fabrication of working electrode used in detection of glutamate and ascorbic acid. Ti-doped $\mathrm{ZnO}$ particles with the average size of $44.47 \pm 4.05$ nanometers were synthesized by the solution combustion technique. Hydrothermal impregnation was employed in preparation of the MWCNT/Ti-doped ZnO composite. Electrocatalytic activities of the MWCNT/Ti-doped ZnO composite were examined using cyclic voltammetry technique. The cyclic voltammograms revealed the reduction reaction of glutamate close to $-0.5 \mathrm{~V}$, whereas the reduction reaction of ascorbic acid close to 0.05 . Fair electrocatalytic performance, with acceptable sensitivity, limit of detection and selectivity suggested potential utilization of MWCNT/Ti-doped $\mathrm{ZnO}$ nanocomposite in detection of ascorbic acid and glutamate.

\section{Full Text}

Due to technical limitations, full-text HTML conversion of this manuscript could not be completed. However, the manuscript can be downloaded and accessed as a PDF.

\section{Figures}

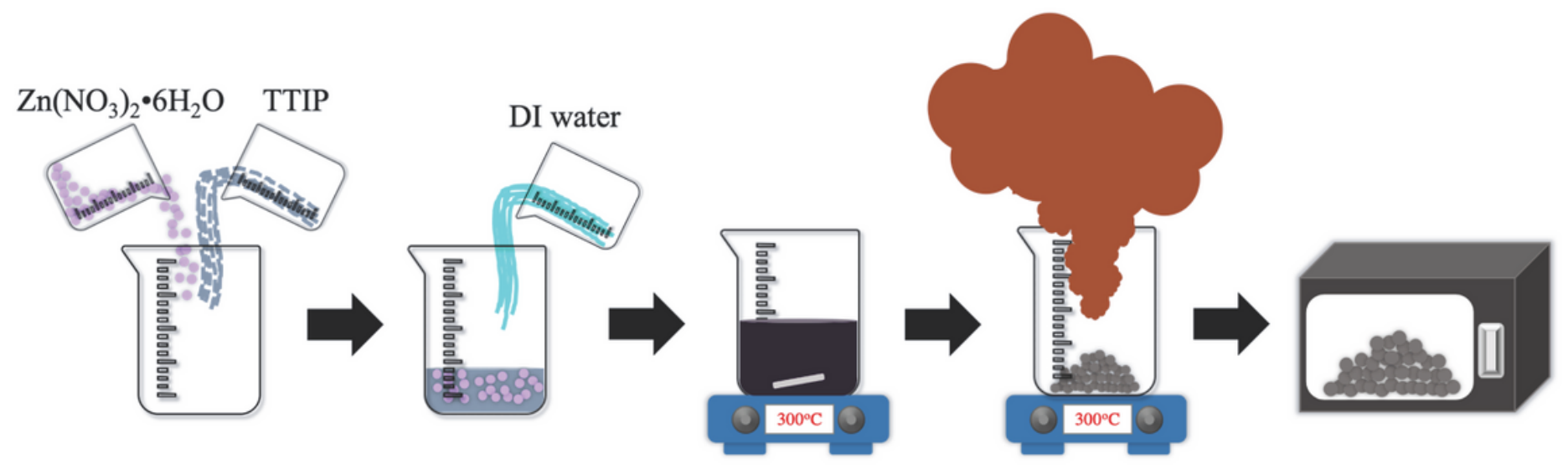

\section{Figure 1}

Schematic of the synthesis of undoped $\mathrm{ZnO}$ and $3 \mathrm{~mol} \%$ Ti-doped $\mathrm{ZnO}$ powders. 
undoped $\mathrm{ZnO}$ or

3 mol\% Ti-doped $\mathrm{ZnO}$

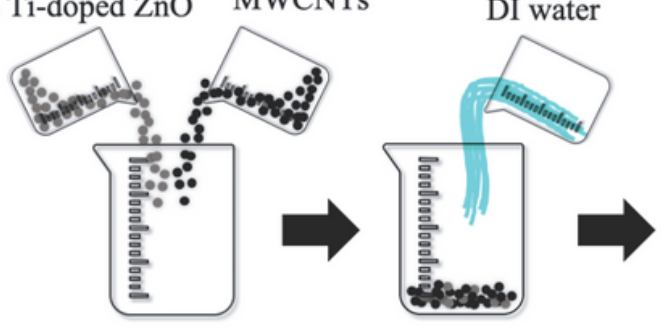

MWCNT/ZnO or MWCNT $/ 3 \mathrm{~mol} \%$ Tidoped $\mathrm{ZnO}$

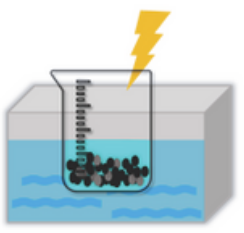

Ethanol
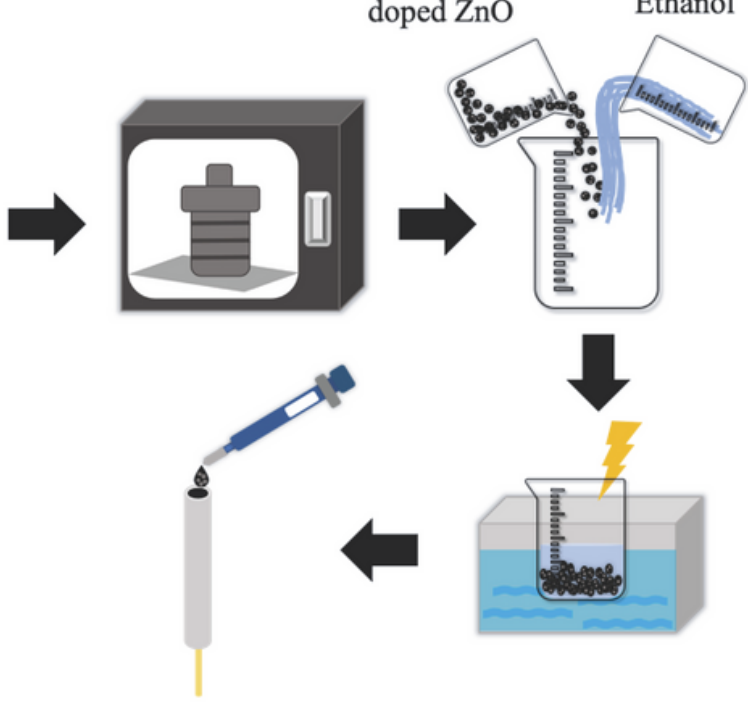

Figure 2

Schematic showing the steps for preparing MWCNT/undoped ZnO and MWCNT/3 mol\% Ti-doped ZnO electrodes 


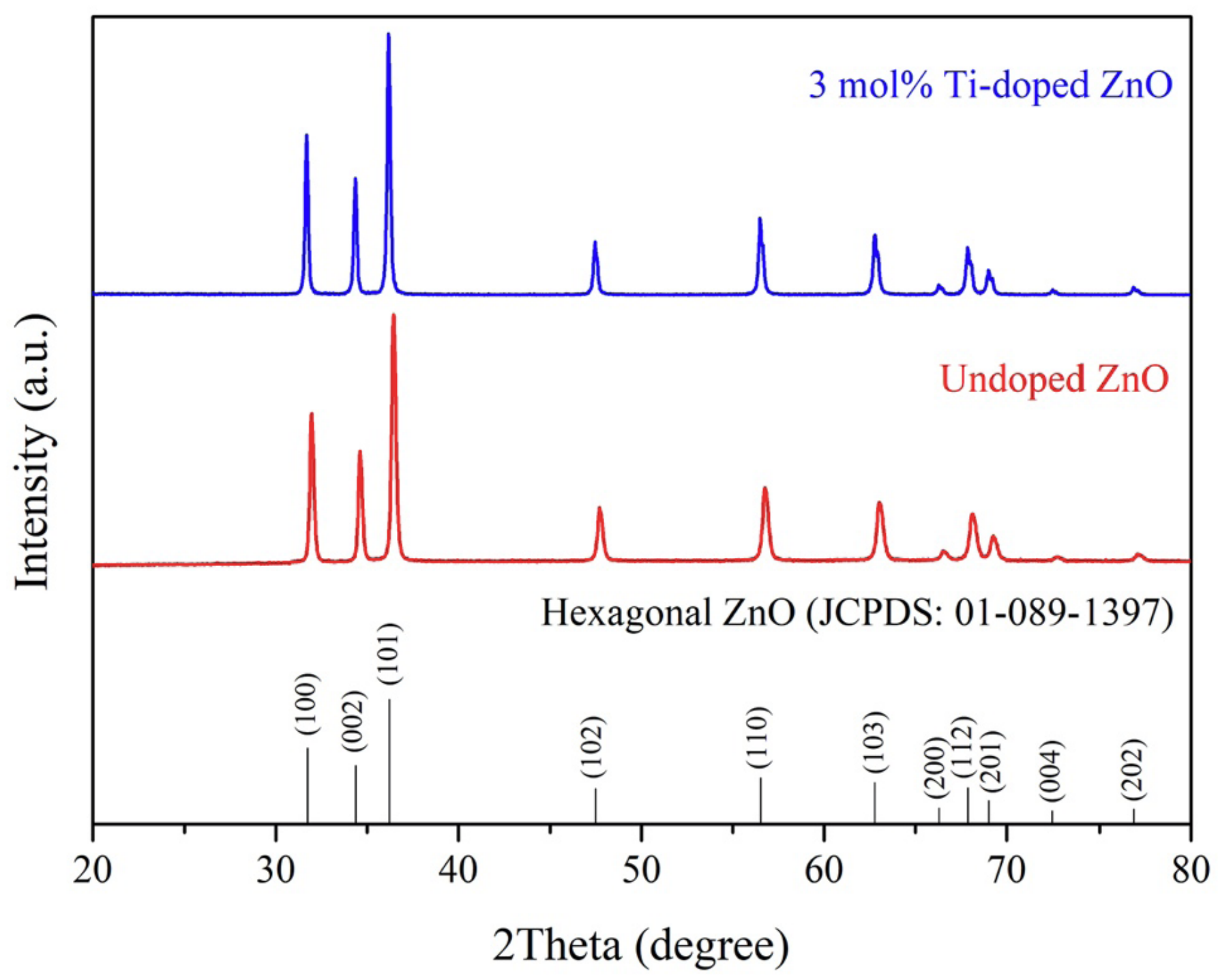

Figure 3

$\mathrm{X}$-ray diffraction patterns of undoped $\mathrm{ZnO}$ and $3 \mathrm{~mol} \%$ Ti-doped $\mathrm{ZnO}$ 

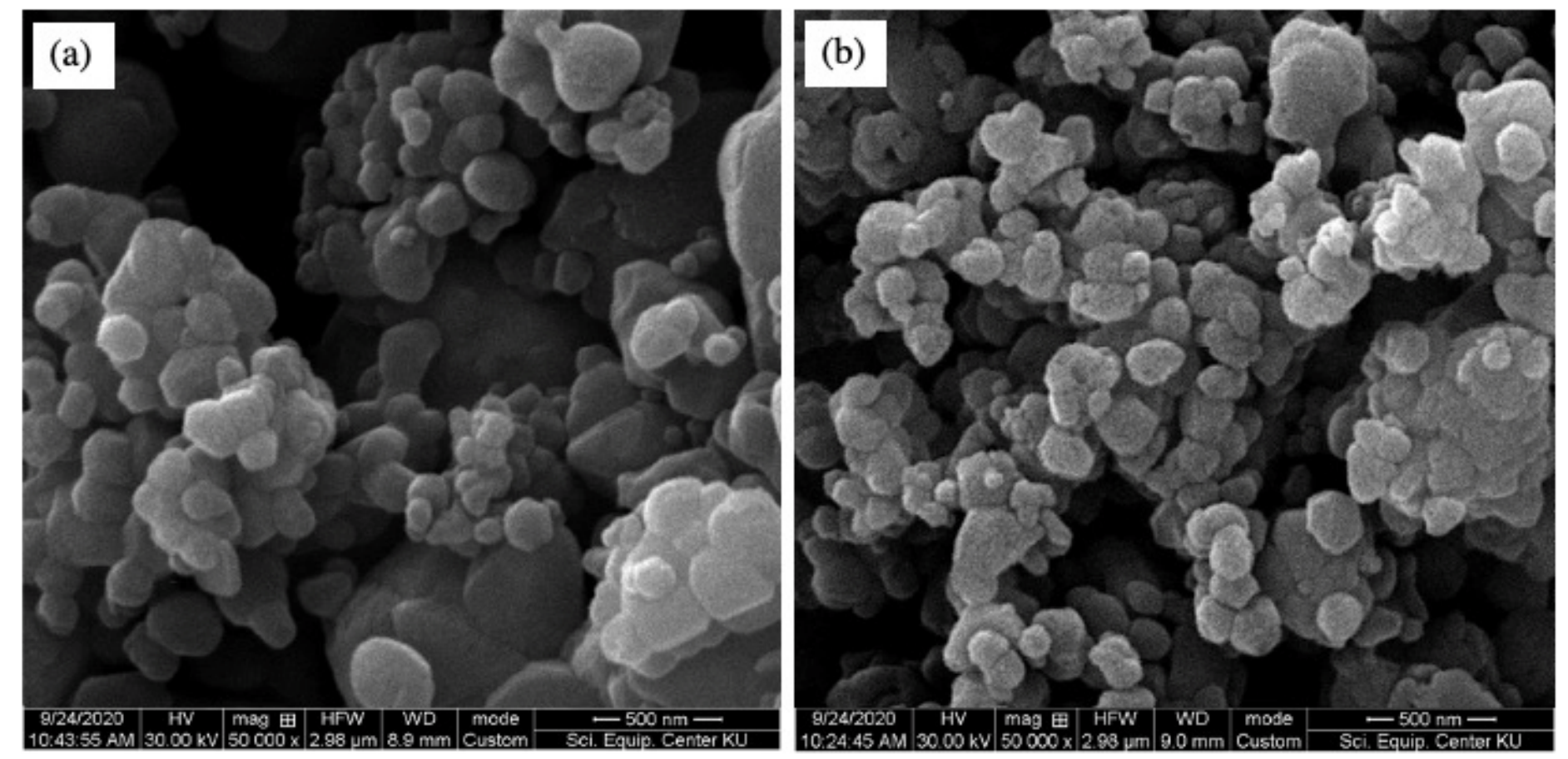

\section{Figure 4}

Scanning electron micrographs of (a) undoped $\mathrm{ZnO}$ and (b) 3 mol\% Ti-doped $\mathrm{ZnO}$
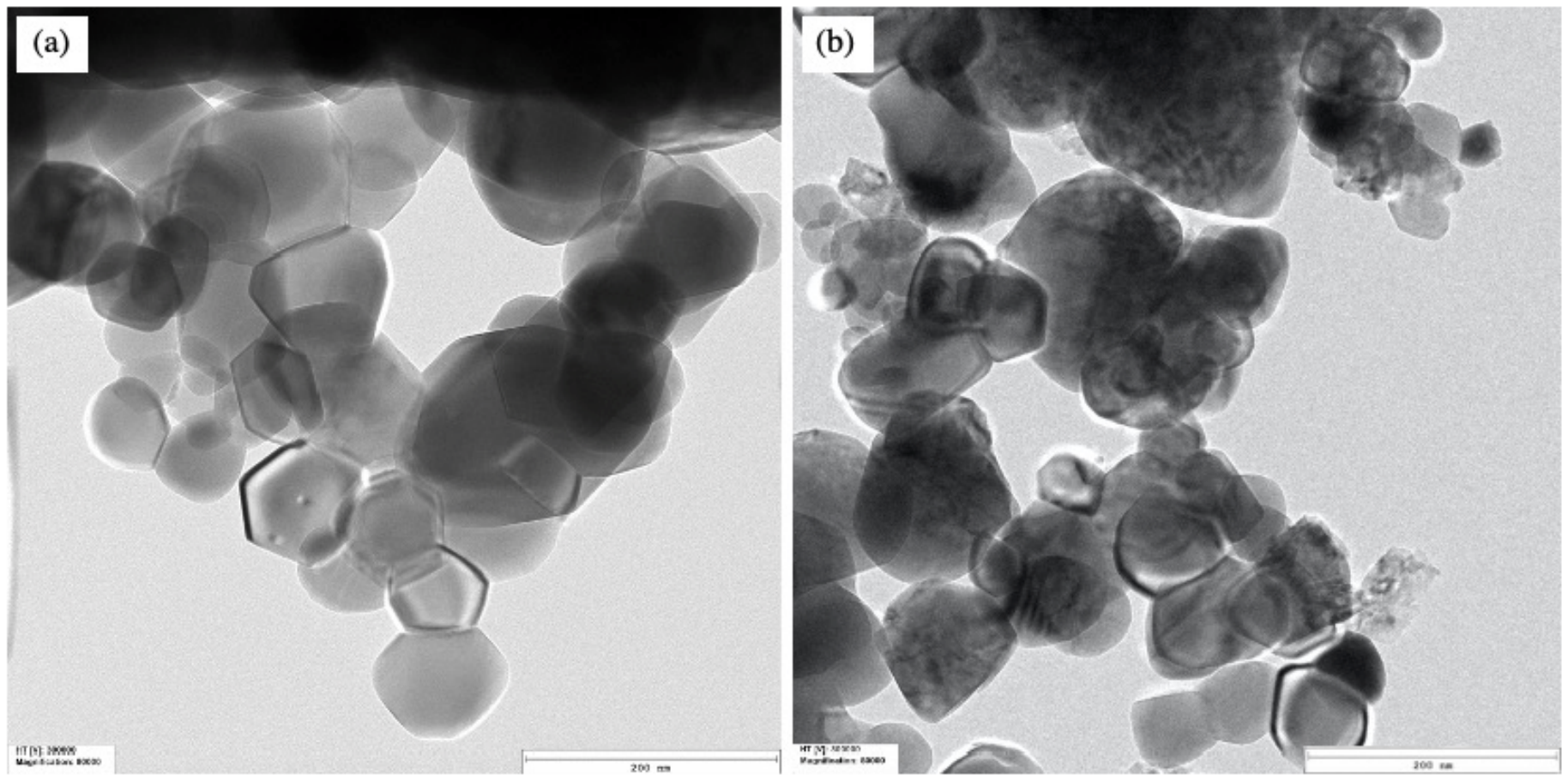

\section{Figure 5}

Transmission electron micrographs of (a) undoped $\mathrm{ZnO}$ and (b) 3 mol\% Ti-doped $\mathrm{ZnO}$ 


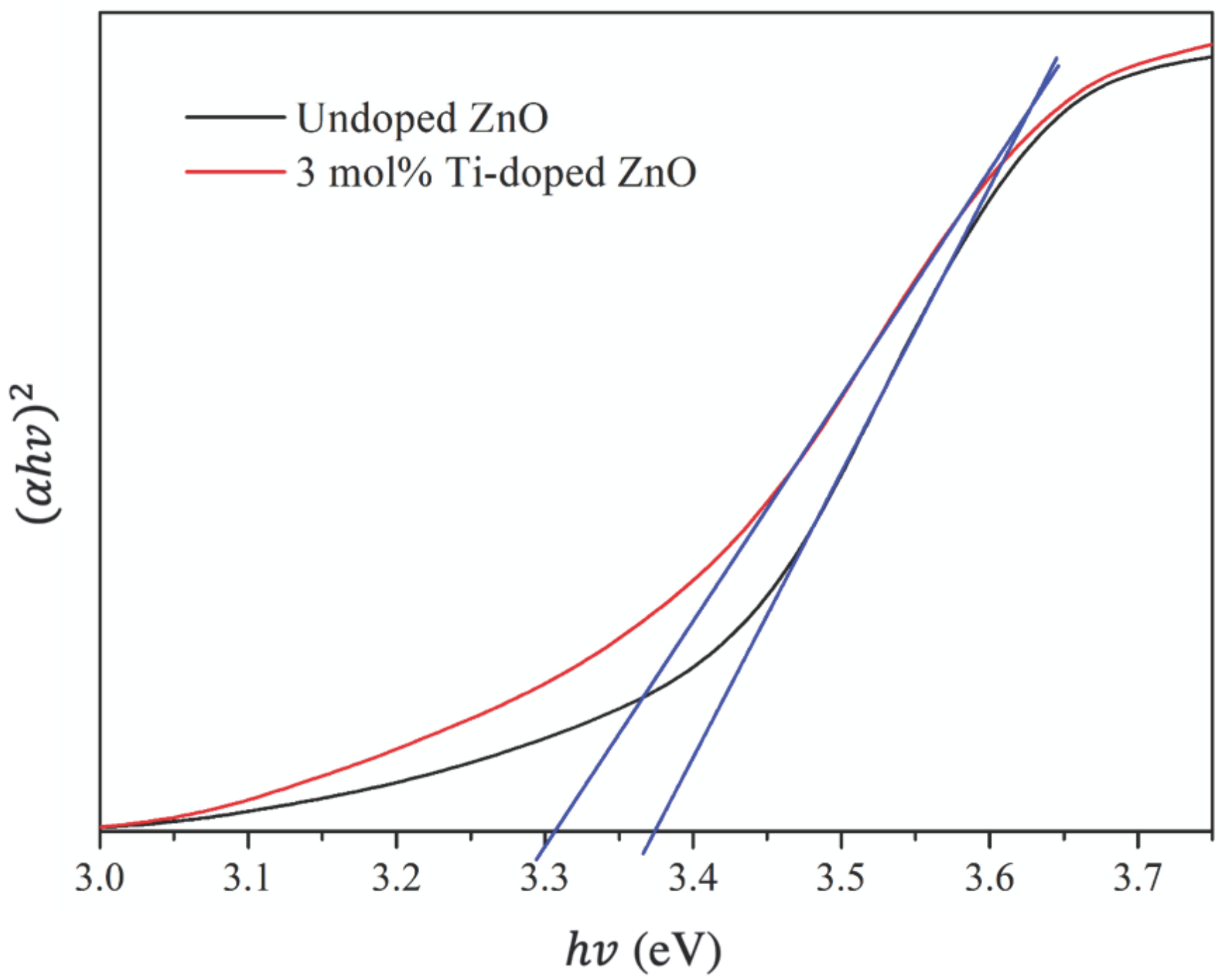

Figure 6

Tauc plots used to determine the bandgap energies of undoped $\mathrm{ZnO}$ and $3 \mathrm{~mol} \%$ Ti-doped $\mathrm{ZnO}$ 


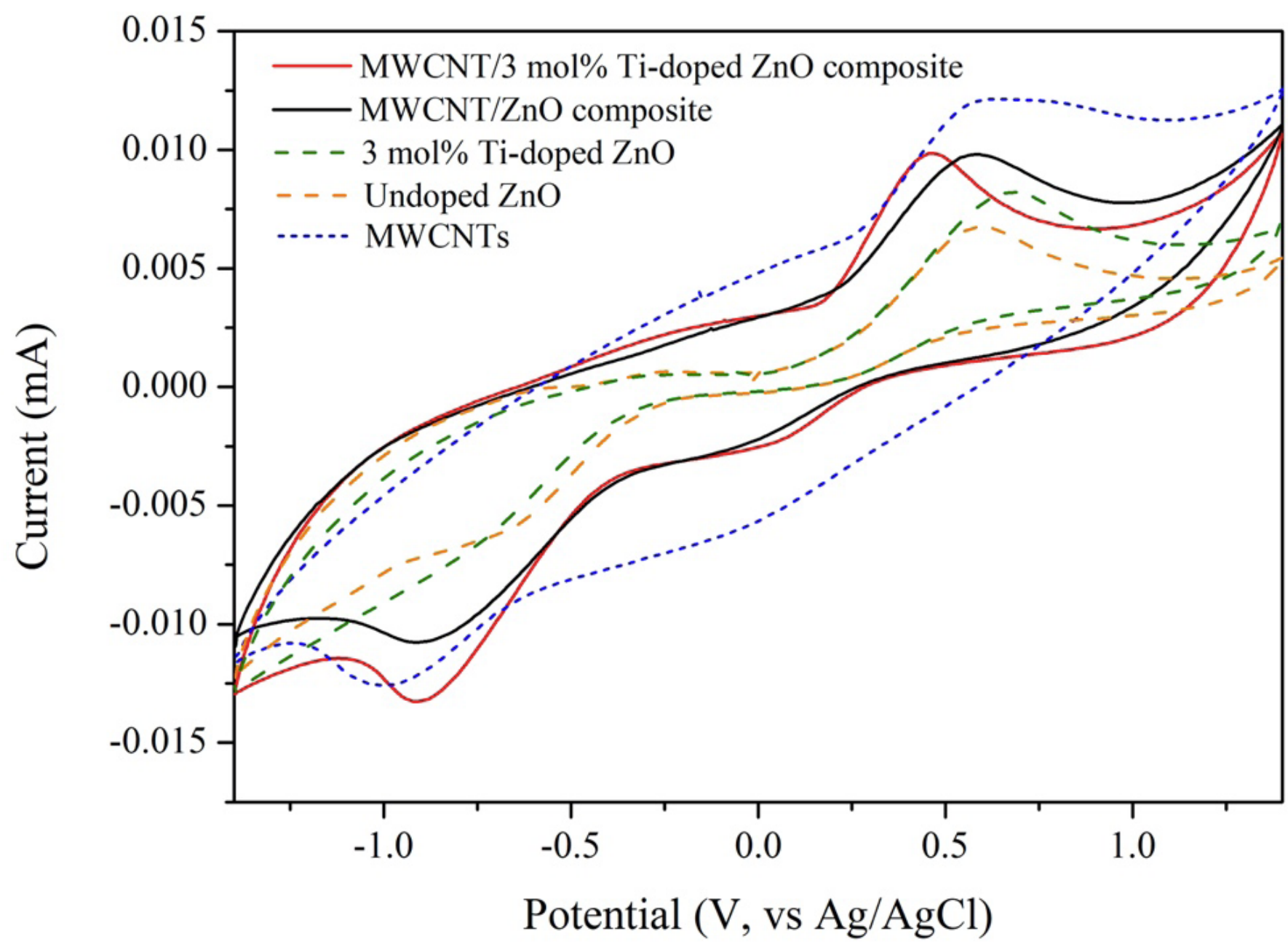

Figure 7

Cyclic voltammograms of MWCNTs, MWCNT/ZnO, and MWCNT/3 mol\% Ti-doped ZnO electrodes in the presence of $500 \mu \mathrm{M}$ ascorbic acid (AA), as recorded at a scan rate of $100.0 \mathrm{mV} / \mathrm{s}$ 

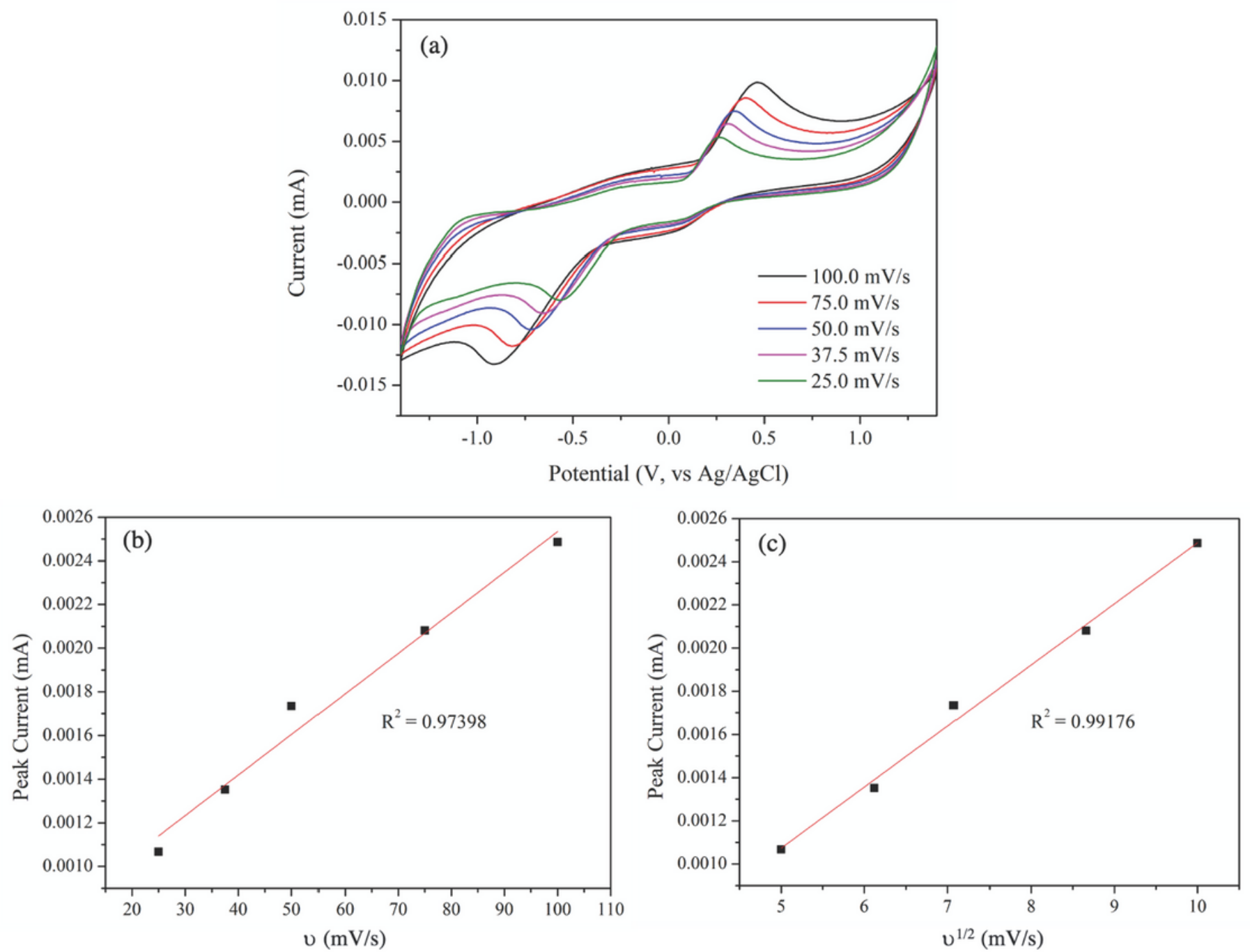

Figure 8

(a) Cyclic voltammograms of the MWCNT/3 mol\% Ti-doped $\mathrm{ZnO}$ electrode at scan rates ranging from 25.0 to $100.0 \mathrm{mV} / \mathrm{s}$; (b) the relationship between the peak current and the scan rate of the reduction reaction at $0.05 \mathrm{~V}$ in $500 \mu \mathrm{M} \mathrm{AA}$; (c) the relationship between the peak current and the square root of the scan rate of the reduction reaction at $0.05 \mathrm{~V}$ in $500 \mu \mathrm{M} \mathrm{AA}$ 

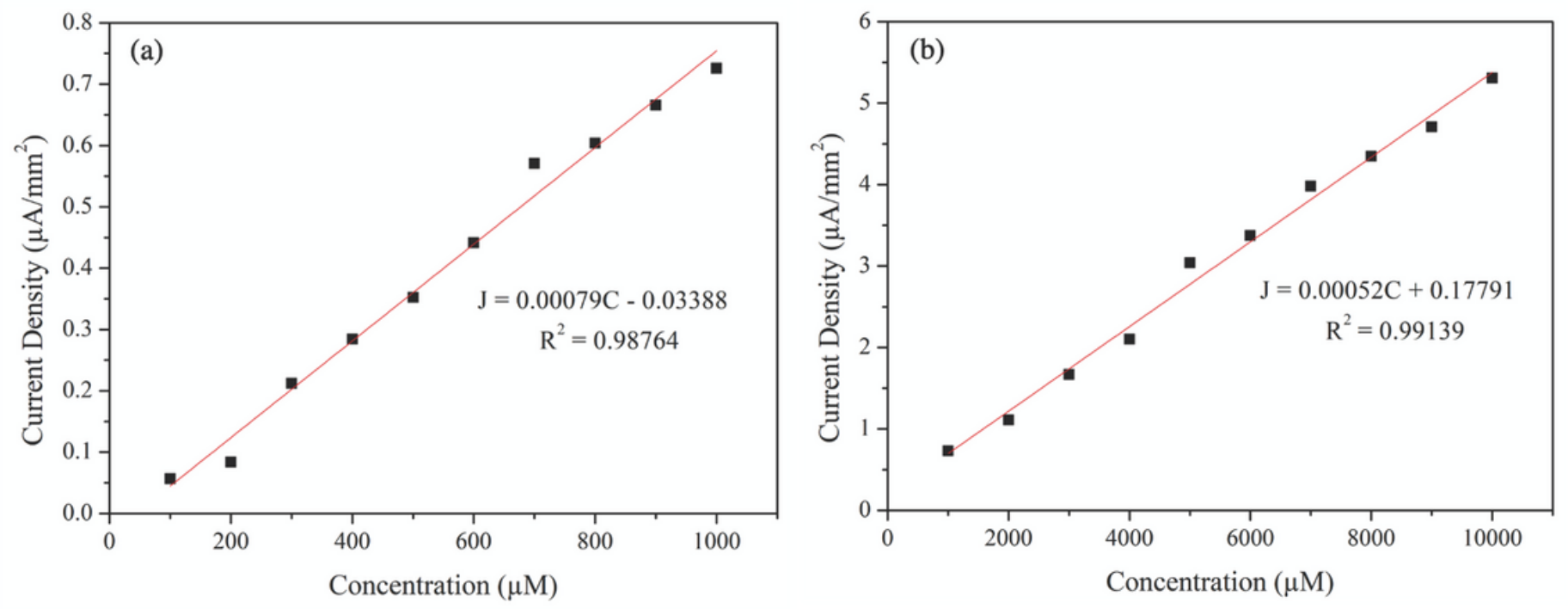

Figure 9

Calibration curves for the MWCNT/3 mol\% Ti-doped ZnO in AA solutions with concentrations of (a) 100$1000 \mu \mathrm{M}$ and (b) $1000-10000 \mu \mathrm{M}$, as recorded at a scan rate of $100.0 \mathrm{mV} / \mathrm{s}$

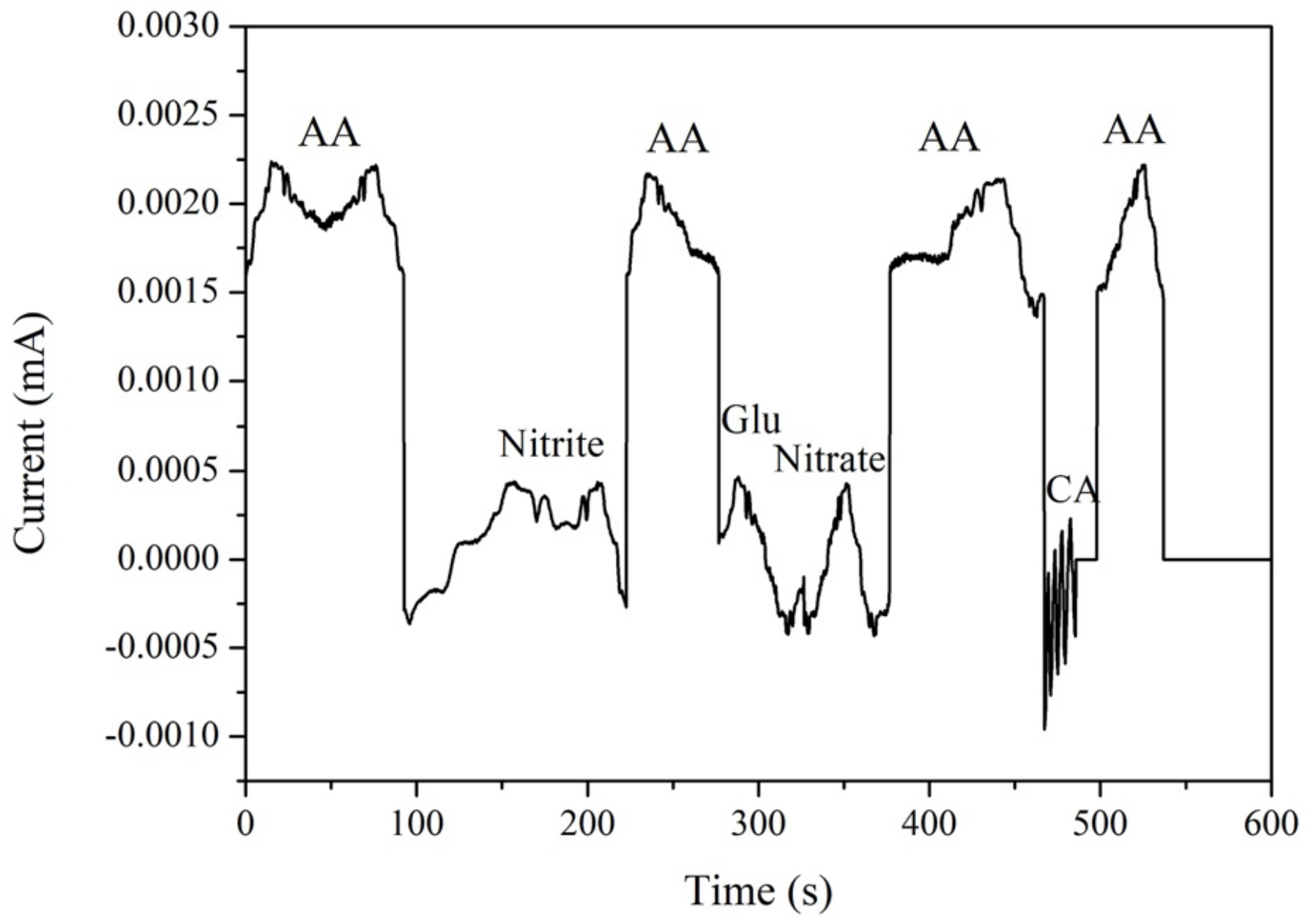

Figure 10 
Selectivity of a MWCNT/3 mol\% Ti-doped ZnO electrode in the detection of $500 \mu \mathrm{M}$ ascorbic acid (AA), $500 \mu \mathrm{M}$ glutamate (Glu), $500 \mu \mathrm{M}$ nitrite, $500 \mu \mathrm{M}$ nitrate, and $500 \mu \mathrm{M}$ citric acid (CA)

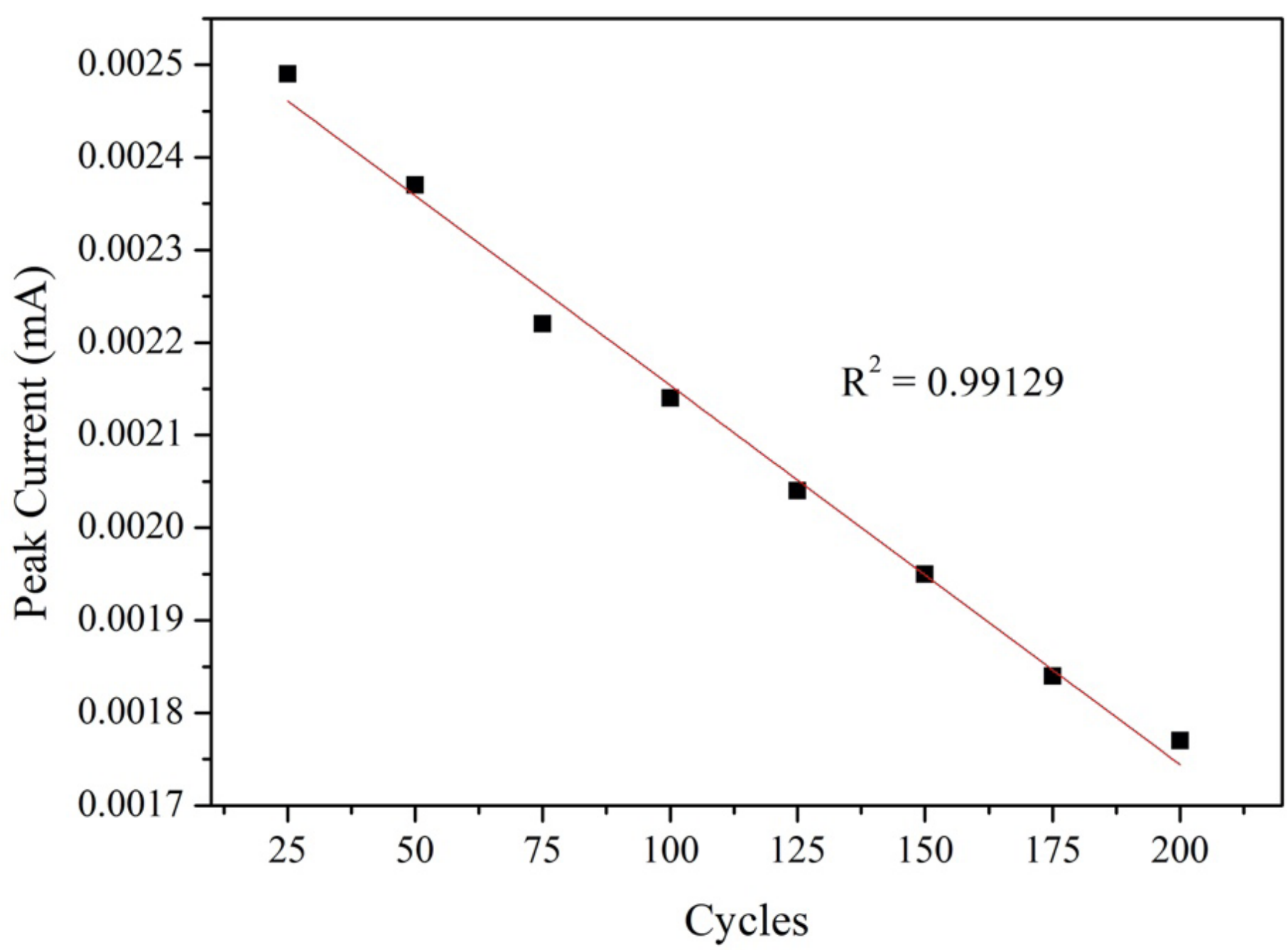

Figure 11

Reusability of the MWCNT/3 mol\% Ti-doped ZnO electrode in $500 \mu \mathrm{M}$ AA at a scan rate $100.0 \mathrm{mV} / \mathrm{s}$ 


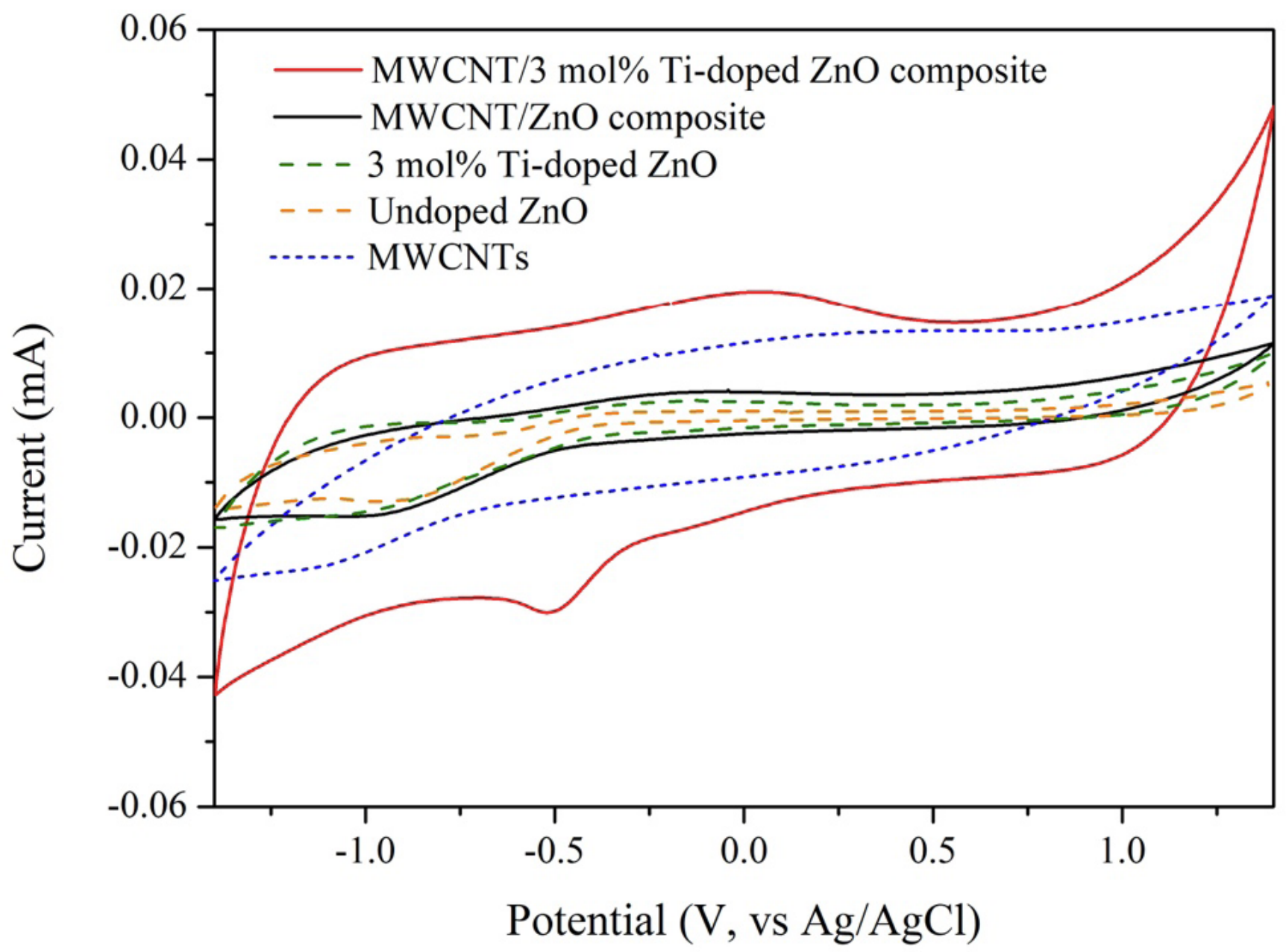

Figure 12

Cyclic voltammograms of MWCNTs, MWCNT/ZnO, and MWCNT/3 mol\% Ti-doped ZnO electrodes in the presence of $500 \mu \mathrm{M}$ glutamate, as recorded at a scan rate of $100.0 \mathrm{mV} / \mathrm{s}$ 

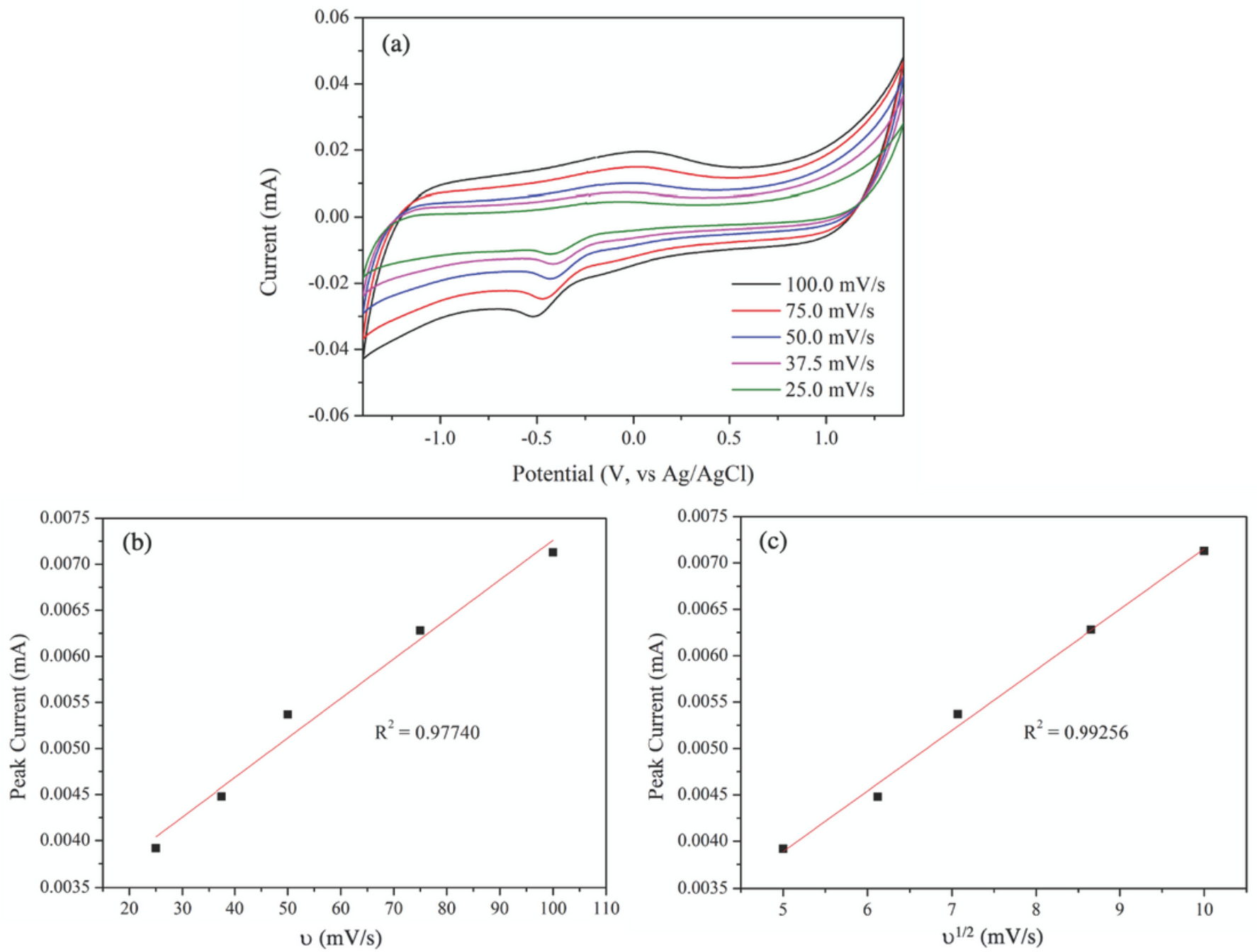

Figure 13

(a) Cyclic voltammograms of MWCNT/3 mol\% Ti-doped $\mathrm{ZnO}$ electrodes at scan rates ranging from 25.0 to $100.0 \mathrm{mV} / \mathrm{s}$; (b) the relationship between the peak current and the scan rate of the oxidation reaction at $-0.5 \mathrm{~V}$; (c) the relationship between the peak current and the square root of the scan rate of the reduction reaction at $-0.5 \mathrm{~V}$ in $500 \mu \mathrm{M}$ glutamate 

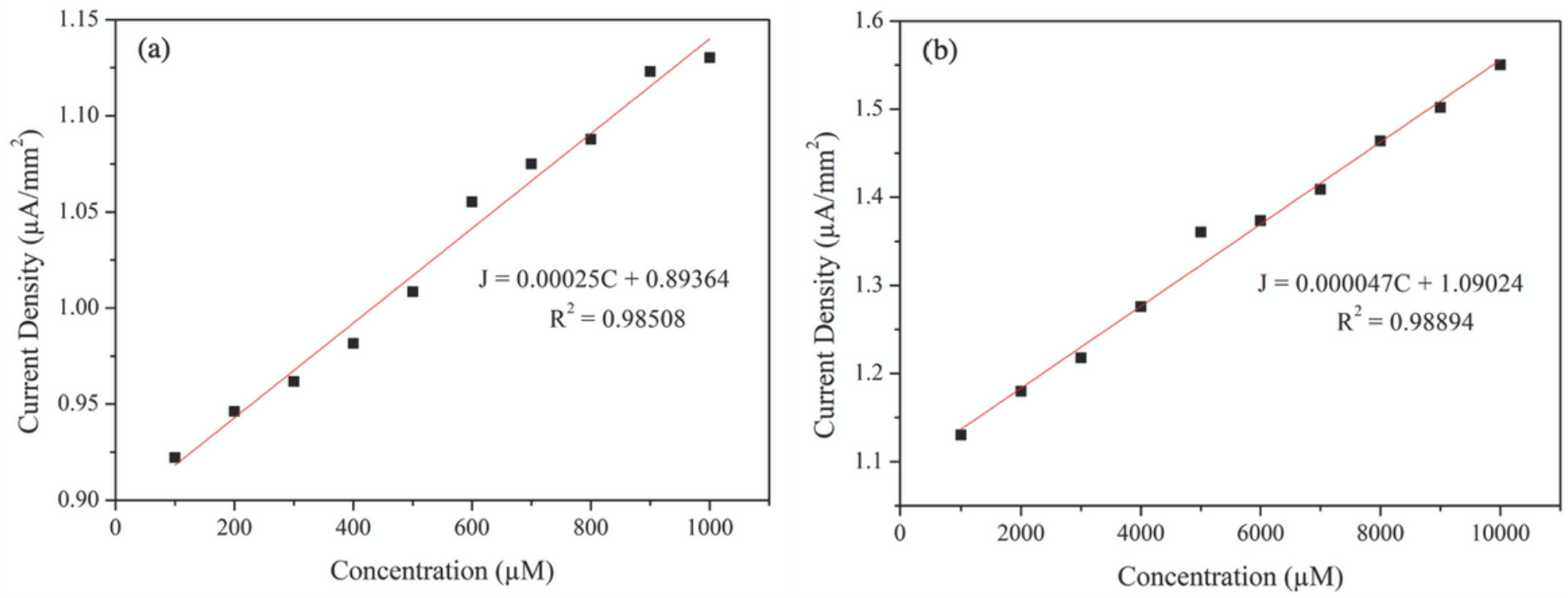

Figure 14

Calibration curves of the MWCNT/3 mol\% Ti-doped $\mathrm{ZnO}$ electrode in glutamate at concentrations ranging (a) from 100 to $1000 \mu \mathrm{M}$ and (b) from 1000 to $10000 \mu \mathrm{M}$, as recorded at a scan rate $100.0 \mathrm{mV} / \mathrm{s}$

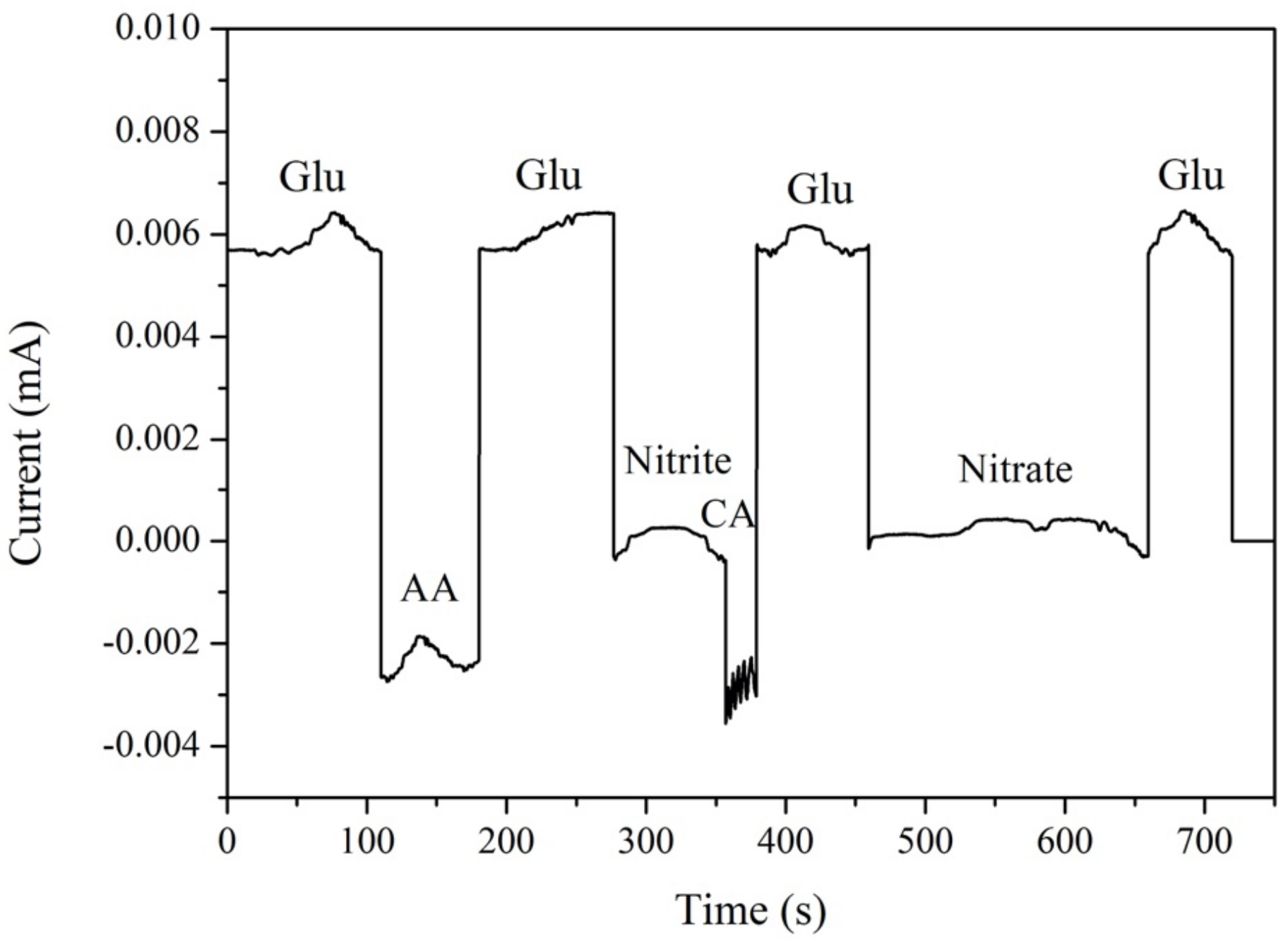


Figure 15

Selectivity of the MWCNT/3 mol\% Ti-doped ZnO electrode in the detection of $500 \mu \mathrm{M}$ (Glu), $500 \mu \mathrm{M} \mathrm{AA}$, $500 \mu \mathrm{M}$ nitrite, $500 \mu \mathrm{M}$ nitrate, and $500 \mu \mathrm{M} \mathrm{CA}$

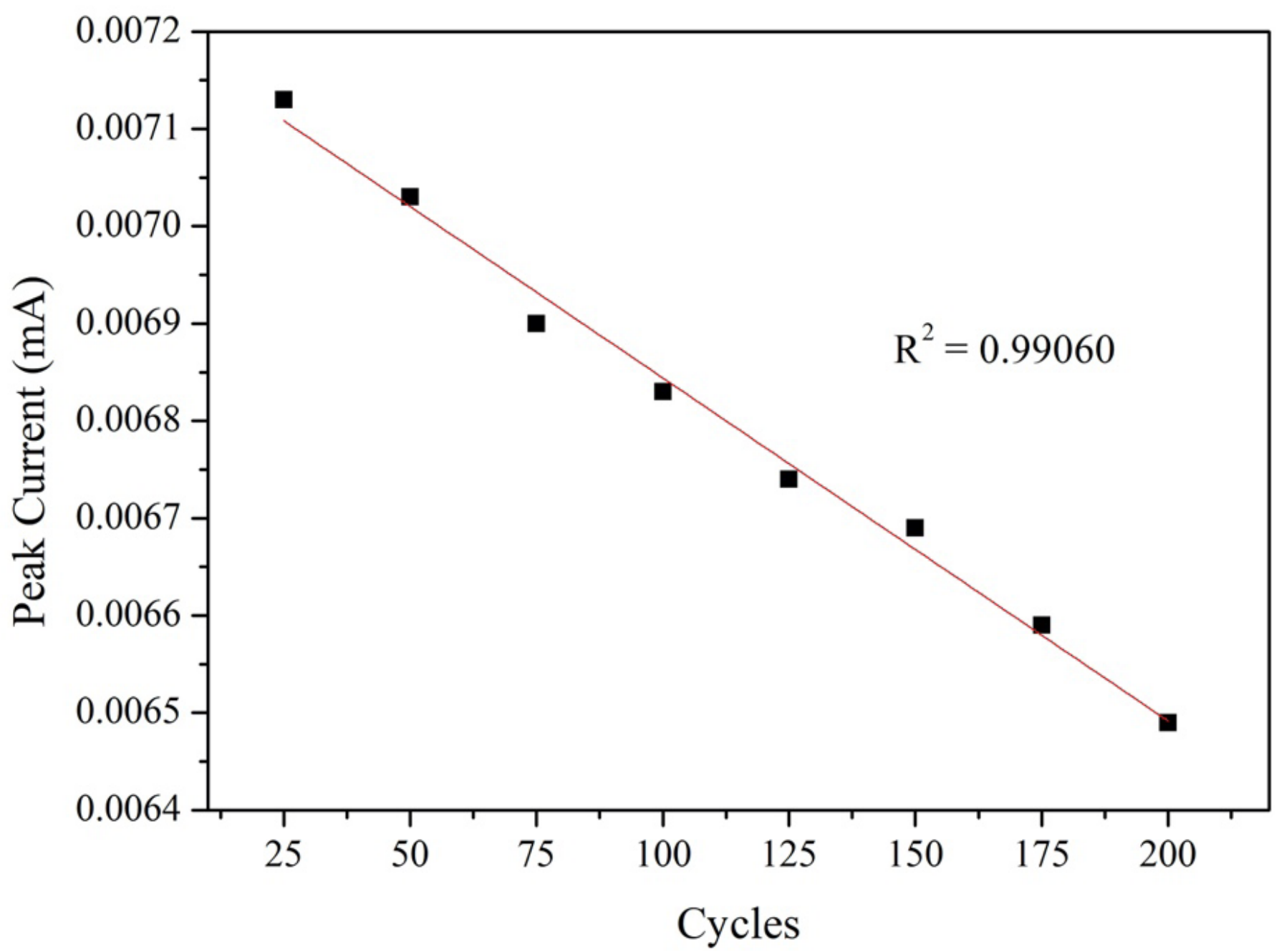

Figure 16

Reusability of the MWCNT/3 mol\% Ti-doped ZnO electrode in $500 \mu \mathrm{M}$ glutamate at a scan rate 100.0 $\mathrm{mV} / \mathrm{s}$ 